\title{
FOOD PRICES AND THE DEVELOPMENT OF MANUFACTURING IN INDIA
}

\author{
Richard Grabowski*
}

\begin{abstract}
Structural change associated with rapid growth has not occurred in labour-intensive manufacturing in India. It is argued in the present paper that this is at least partly due to the rise in the relative cost of labour, which is the result of the rising cost of food stemming from rapid overall growth and sluggish growth in agricultural productivity. A theoretical model has been developed and the experience of India is used to illustrate the model and its implications.
\end{abstract}

JEL classification: $01,05, \mathrm{Q} 1$.

Keywords: India, food prices, manufacturing.

\section{INTRODUCTION}

Economic growth over extended periods of time tends to be accompanied by dramatic structural change. Initially, poor countries are dominated by the agricultural sector. This sector makes up a large proportion of gross domestic product (GDP) and employment. Rapid growth in GDP is usually accompanied by a decline in the share of agriculture in GDP and employment. The fall in the share of agriculture in GDP generally declines more rapidly than the share of agriculture in total employment, but as employment in modern manufacturing and services rapidly grows, labour in the agricultural sector gravitates to the manufacturing and services sectors at a quick pace. This is because manufacturing is initially labour intensive in nature. Ultimately, the service sector becomes the dominant economic activity as modern services replace traditional, labour-intensive services and manufacturing. Of course, the growth process does not necessarily unfold in such a manner. Initial conditions, such as the relative abundance of land, may have a significant influence on the type of structural change that takes place (Dorin, Hourcade and Benoit-Cattin, 2013).

\footnotetext{
Department of Economics, Southern Illinois University, Carbondale, Illinois 62901 (e-mail: ricardo@ siu.edu).
} 
Recently, this structural change process has seemingly gone awry and the feasibility of this path of economic development has been called into question. Consequently, it may no longer be possible for a country to utilize rapid growth in manufacturing to absorb labour from agriculture and provide productive employment without significant policy changes. Rodrik (2014) has shown that manufacturing as a share of GDP and employment in many developing countries is failing to achieve the levels attained by East and South-East Asia during their periods of rapid growth and structural change. More specifically, in many developing countries, manufacturing as a share of GDP and employment appears to be declining, which is raising fears of a deindustrialization process.

This is important for a number of reasons. If rapid growth is achieved without rapid expansion in labour-intensive activities, such as manufacturing, how will this labour be productively incorporated into the economy? In addition, much of the early growth in poor countries comes from shifting labour from agriculture, where labour productivity is low, to manufacturing where labour productivity is much higher. This is a comparative static gain from shifting labour from one sector to another. Furthermore, there is a dynamic gain from this shift, which has been documented by Rodrik (2013), who has shown that unconditional convergence in labour productivity tends to occur in manufacturing. That is, once a manufacturing sector is firmly established in a less developed region, labour productivity in that sector tends to converge to that found in that same sector in developed countries. Thus, aggregate (economy-wide) convergence generally fails to occur in many low income countries because manufacturing remains too small of a share in the overall economy. Therefore, there is a dynamic gain and a comparative static gain in labour productivity that results from shifting labour. These gains will be lost if the structural change breaks down.

India also has experienced a structural change process that is quite different from the experiences in East and South-East Asia and the currently developed countries. In the case of India, economic growth has been characterized by the rapid expansion of modern sector services. Manufacturing, especially labour-intensive manufacturing, has failed to grow rapidly. In addition, the existing modern industrial sector has become increasingly capital intensive in nature (Kochhar and others, 2006). Direct employment in agricultural production has declined, but much of the labour, which had worked in agriculture, is involved in rural, non-farm, informal economic activities. Some scholars have labelled this as "stunted structural transformation" (Binswanger-Mkhize, Peter and D’Sousa, 2011).

Therefore, how can the lack of development of labour-intensive manufacturing in today's developing countries be explained? One set of arguments emphasizes the changes in technology that have occurred. This change in technology allows for the 
production of a good to be broken into pieces, which are located in various parts of the world, resulting in less development of manufacturing in any particular place (Baldwin, 2011). Labour-intensive technologies are also being replaced with those requiring less labour. Even for those manufactured goods that have been characterized as labour intensive, technical innovation seems to be capital intensive in nature (Felipe, Mehta and Rhee, 2014). In addition, in many places in the world, government regulations have made physically abundant labour economically expensive to use. This has made it very difficult for labour-intensive manufacturing to expand. All of these factors have certainly played a role, but in the present paper, an additional explanation is developed, which is based on the cost of food.

The argument is fairly straightforward. A three-sector model composed of food producing agriculture, services, and manufacturing is developed. The service sector is closed to trade, while manufacturing and agriculture are open to trade. An exogenous increase in food prices is allowed to occur. An implication of the model is that labour will flow into agriculture and out of manufacturing while the service sector will maintain its share of labour. As a result, manufacturing will decline or, in other words, deindustrialization will occur.

A second version of the model is developed in which the service and manufacturing sectors are assumed to be human capital intensive (modern) and open to trade. The food production sector is also open, but the large country case is assumed. An exogenous external increase in the demand for modern services will lead to a rise is the relative price of food. As a result, once again the manufacturing sector will decline.

The models are then applied to the experience of India. A discussion of the trend in manufacturing and structural change is presented. Data on food inflation and real wages are examined. The conclusion drawn indicates that increases in the price of food have made labour more expensive, making it difficult to develop a comparative advantage in labour-intensive manufacturing.

This paper unfolds as follows. In the second section, the theoretical basis of the paper is developed. Section III applies the model to the experience of India. Finally, section IV contains a summary of the paper and a discussion of policy implications.

\section{SOME THEORETICAL ANALYSIS}

Much of classical economics and modern dualistic economic analysis has been concerned with agriculture, the price of food and structural change. Ricardo (1965) has focused heavily on the operation of the law of diminishing returns in 
agriculture and how that would affect the growth of manufacturing. Lowering corn prices through the elimination of the Corn Laws was seen as a mechanism for promoting prosperity in England. Although without technical innovation, such prosperity might have been short-lived.

Dualistic models based on the classical perspective also tend to place importance on the role of food in the process of economic development. In the model of dualistic economic development developed by W. Arthur Lewis, the economy is divided into modern and traditional sectors. The modern sector uses capital and labour, saved and accumulated capital and maximized profit. Although Lewis argued that this sector is composed of many different types of products, others have generally identified it with manufacturing (Lewis, 1954). The traditional sector, which is often identified with agriculture, especially food production, utilizes land and labour, engages in no savings, is characterized by output sharing rather than profit maximizing, and is burdened with surplus labour. Assuming a closed model with no technological innovation, growth occurs as the result of the shift of labour from agriculture, in which the marginal product of labour is zero or very low as compared to the manufacturing sector which has greater labour productivity. As a result, growth comes from structural change.

As long as surplus labour exists, food problems do not arise. However, once it is exhausted, food production declines, which puts upward pressure on real wages in the modern manufacturing sector. This, in turn, threatens the expansion of manufacturing and thus the source of growth and structural change may likely be inhibited. Consequently, in this type of model a sort of balanced growth process is needed. Most importantly, productivity in agriculture, in particular food staples, is the key to enabling the structural change process to unfold. There are many criticisms one can make of this sort of analysis. The meaning of the concept of surplus labour has been debated heavily and doubt has been cast on its empirical validity. In addition, the model, as outlined, is closed in nature. If the model economy is opened to trade and assuming a small country case, the situation changes. Saving and investment in manufacturing result in a shift of labour (structural change), but food prices are fixed by imports. If a comparative advantage in manufacturing is developed, then exports from this sector can be used to finance the imports of food. Under this scenario, structural change can successfully occur as food loses its importance in the development story.

Models can be developed in a way that would not be subject to those criticisms and allow the production of food staples to continue to play a critical role in the process of structural change. The series of models explained here are based on the work of Gollin, Jedwab and Vollrath (2013). The first model to be discussed is of a three sector economy: agriculture (staple food production), labour-intensive 
manufacturing, and services, which are also assumed to be labour intensive in nature. The latter is a traditional service sector, which is labour intensive and produces services on a small scale (not modern sector services, such as banking and finance). The economy is open to international trade in terms of manufacturing and food staples, but closed in terms of the service sector. It is assumed that these types of services are non-tradable.

Although the staple food sector is open to trade, the large country case is being assumed. That is, increased purchases or sales of food can influence the domestic price of food. This assumption is made because India is indeed a large country, geographically and in terms of population. In addition, the international markets for most food staples are very thin in nature. Trade in most food staples is relatively limited because few developing nations wish to rely on imports to meet a significant part of their food needs. In 2000, almost 70 per cent of the arable land in developing countries was devoted to food staples (grains, pulses, roots and tubers). Of this production, almost all of it was devoted to domestic consumption. Few developing nations are exporters of grain. For example, Argentina has been exporting more than a quarter of its grain crop (Gollin, Parentz and Rogerson, 2007) while Brazil has become a major exporter of corn. As a result, international markets are thin and changes in purchases by any large economy are likely to have dramatic effects on the domestic prices of particular food staples.

The manufacturing (labour-intensive) sector is also assumed to be open to trade, but the small country case is assumed here and prices are, therefore, exogenous. It is initially assumed that the country has a comparative disadvantage in food and thus is an importer. Alternatively, the country is also assumed to have a comparative advantage in labour-intensive manufacturing, that is, the country is relatively labour abundant. Of course, even countries that are labour abundant do not automatically have a comparative advantage in labour-intensive manufacturing. Infrastructure must be provided, market failures must be compensated for and coordination problems must be solved. Thus, the state plays a critical role in the development of this comparative advantage.

Food-producing agriculture is assumed to utilize land and labour in the production process. Manufacturing and services both use only labour. However, the former provides a tradable good and the latter a non-tradable good.

In this context, when assuming an exogenous increase in the relative price of food, there is a large shock in terms of prices. This, in turn, results in the expansion of domestic food production which would require increased amounts of labour. This labour cannot come from the service sector as its output is non-tradable and the labour associated with it must remain in that sector in order to produce the same level 
of services. Actual service production may need to expand as these traditional services are usually associated with the production and processing of food. Real wages in food production and possibly the traditional service sector will rise and labour will be drawn from the manufacturing sector with production in that sector declining. This basically involves the undermining of the developing country's comparative advantage in labour-intensive manufacturing. One might call this a process of deindustrialization as the capability to produce labour-intensive manufacturing has declined.

A variation on the above model can be developed by adding a modern service sector, which utilizes only human capital as an input in the production process while subsuming the traditional service sector into the food production sector. It is assumed that the country has a comparative advantage in modern sector services, a potential comparative advantage in manufacturing, and a comparative disadvantage in food production.

In this context, a dramatic rise in external demand for modern sector services will have a number of effects. In particular, production and income in this sector will rise. Increased income is presumed to be spent on food, manufactured goods, and traditional services. Thus, the food and traditional services sectors will require additional labour to expand production. This labour will have to be drawn from the manufacturing sector, as the increased demand for this sector's output will be met by imports. This will be accomplished through a rise in the relative price of food and in real wages in this sector relative to manufacturing. This will likely undermine the potential comparative advantage that manufacturing has and thus result in deindustrialization, in the sense of reduced capability to produce.

It should be pointed out that the rising wages discussed above are likely, in the long run, to lead to an increase in mechanization of the production process in agriculture. As a result, employment opportunities are likely to grow slowly in that sector in the long term. Consequently, much of the expansion in employment will likely be in traditional services.

In the two scenarios outlined above, the price of food plays a critical role in the analysis. Rising food prices resulting from an exogenous shock or as the result of the rapid expansion of another sector of the economy (modern services) draws resources away from and undermines the comparative advantage in manufacturing. Rapid productivity growth in the food sector, which leads to a reduction in the relative price of food and real wage costs in manufacturing, makes maintaining or developing a comparative advantage in manufacturing more likely. 
In the next section of the paper, this analysis is illustrated through the experiences of India during the period since the emergence of higher growth rates. The discussion shows that labour intensity in manufacturing in India has declined, partly as a result of rising real wages associated with an increase in the relative price of food.

\section{AN INDIAN EXAMPLE}

Beginning in the 1980s, India has been experiencing a period of relatively rapid economic growth, which represents a dramatic change from the past. As a result, structural change has indeed occurred in the economy. The share of agricultural production in GDP fell from 41.1 per cent in 1972-1973 to 14.1 per cent in 2011-2012. This has also been matched by a decline in the share of employment in agricultural activities from 73.9 per cent in 1972-1973 to 48.9 per cent in 2011-2012 (Reddy, 2015). This is just what one would expect to occur as the growth and development process unfold.

However, the decline in the proportion of labour employed in agriculture has not been accompanied by an increase in manufacturing as a share of either total employment or production. This contradicts the process of structural change followed by countries in East Asia and South-East Asia. In those countries, the relative contraction in agriculture as a share of production and employment was accompanied by a rise in manufacturing as a share of production and employment (as well as a rise in modern sector services). The result of this process of structural change has been rapid growth in employment opportunities outside of agriculture. The case of the Republic of Korea is a good example of this process (Amirapu and Subramanian, 2015).

The concern for India is that growth that bypasses labour-intensive manufacturing is likely to be growth that generates only a slow increase in employment opportunities. The view that manufacturing has failed to play the usual role in the development process is supported by the work of Amirapu and Subramanian (2015).

Data on labour productivity in the Indian economy, excluding agriculture, are presented in table 1. As indicated, labour productivity in registered manufacturing has been quite high, only exceeded by that in modern services. Thus, the potential for rapid growth in labour productivity through the shift in resources from agriculture to modern manufacturing and services certainly exists in India. 
Table 1. Growth of labour productivity in India (\%)

\begin{tabular}{lcc}
\hline \multicolumn{1}{c}{ Sector } & $\mathbf{1 9 8 4 - 2 0 1 0}$ & $\mathbf{2 0 0 0 - 2 0 1 0}$ \\
\hline Aggregate economy & 3.7 & 4.0 \\
Non-manufacturing & 3.7 & 3.9 \\
Services & 4.9 & 6.3 \\
Manufacturing & 3.7 & 4.2 \\
Registered manufacturing & 4.4 & 5.4 \\
Unregistered manufacturing & 2.2 & 1.2 \\
\hline
\end{tabular}

Source: Adapted from Amirapu and Subramanian (2015).

However, data reveal that India has not been able to adequately take advantage of the opportunity with respect to manufacturing. Tables 2 and 3 show the share of registered (modern) manufacturing in total employment and in total production. As indicated, the share in terms of employment has actually declined whereas the share in terms of output has increased very little.

The most abundant factor of production in India has been unskilled labour. Only a slim majority of those employed in India have attained a primary level education, while only 20 per cent of workers have had a secondary education. With this skill base, one would expect that the most dynamic sector would likely be labourintensive manufacturing. In the previous paragraphs, it was shown that modern manufacturing growth has been relatively slow and that the increase in manufacturing that has occurred required skilled labour (Kochhar and others, 2006). The registered

Table 2. Growth in employment shares

\begin{tabular}{lccc}
\hline \multicolumn{1}{c}{ Sector } & $\mathbf{1 9 8 4}$ & $\mathbf{2 0 1 0}$ & $\begin{array}{c}\text { Annual growth } \\
\text { (1984-2010) }\end{array}$ \\
\hline Registered manufacturing & .027 & .026 & $-0.2 \%$ \\
Aggregate services & .201 & .219 & $0.3 \%$ \\
Trade, hotel, etc. & .074 & .093 & $0.9 \%$ \\
Communications & .028 & .038 & $1.2 \%$ \\
Financial services and insurance & .006 & .007 & $0.7 \%$ \\
Real estate, business services & .002 & .011 & $7.1 \%$ \\
Construction & .031 & .080 & $3.7 \%$ \\
\hline
\end{tabular}

Source: Adapted from Amirapu and Subramanian (2015). 
Table 3. Growth in output shares

\begin{tabular}{lccc}
\hline \multicolumn{1}{c}{ Sector } & $\mathbf{1 9 8 4}$ & $\mathbf{2 0 1 0}$ & $\begin{array}{c}\text { Annual growth } \\
\mathbf{( 1 9 8 4 - 2 0 1 0 )}\end{array}$ \\
\hline Registered manufacturing & .091 & .195 & $0.6 \%$ \\
Aggregate services & .358 & .528 & $1.5 \%$ \\
Trade, hotel, etc. & .120 & .152 & $0.9 \%$ \\
Communications & .056 & .075 & $1.1 \%$ \\
Financial services and insurance & .035 & .058 & $2.0 \%$ \\
Real estate, business services & .053 & .108 & $2.81 \%$ \\
Construction & .056 & .087 & $1.7 \%$ \\
\hline
\end{tabular}

Source: Adapted from Amirapu and Subramanian (2015).

manufacturing sector is indeed skilled-labour intensive (Amirapu and Subramanian, 2015).

Sen and Das (2014) provide further evidence that the labour intensity of Indian production, in particular manufacturing, has been declining. Evidence of this is given by calculating the output elasticity of employment. From 1990 to 2000, value added in manufacturing grew by 6.7 per cent per year, while employment growth was 1.81 per cent, resulting in an employment elasticity of output of 0.27 . However, from 2000 to 2010 the output elasticity of employment fell to 0.05 .

Sen and Das (2014) calculated the labour to fixed capital ratio for the entire three digit organized manufacturing sector for every year (and for each industry) for the period 1980-1981 to 2009-2010. The average labour intensity ratio for the organized manufacturing sector as a whole was 0.84 . Industries, with ratios above this were classified as labour intensive while those with ratios below this were classified as capital intensive. Sen and Das (2014) show, using this information, that from the 1980 s to 2010 , labour intensity across fifty-two National Industrial Classification (NIC) three digit sectors fell from 1.45 to 0.33 . The pace of decline was the highest for the most labour-intensive sectors (Sen and Das, 2014).

The immediate question that comes to mind is why this has occurred in India. This is in complete contrast to the experiences of East Asia, China, and Viet Nam. Some have argued that this is the result of strict labour laws in the country governing the conditions of employment, which significantly increase the cost of hiring labour. This would induce firms to substitute capital for labour. However, Sen and Das (2014) point out that while this argument relates to the level of capital and labour intensity, it fails to provide an explanation for the decline of labour intensity over time as this 
would require a scenario in which labour laws were to become increasingly inflexible (which does not seem to be the case). They propose an alternative explanation in which the declining labour intensity of production is attributed to a rise in the wage to rental price of capital ratio. Labour has become relatively more expensive or, an alternative way of expressing it, capital has become increasingly cheap. This is why manufacturing has become more capital intensive (less labour intensive).

They calculate the rental rate of capital as follows:

$$
\mathrm{R}_{\mathrm{it}}=\left(\mathrm{PK}_{\mathrm{t}}\left(\mathrm{r}_{\mathrm{t}}-\pi_{\mathrm{t}}\right)\right) / \mathrm{P}_{\mathrm{it}}
$$

Where $\mathrm{PK}_{\mathrm{t}}$ is the price of capital goods in year $\mathrm{t}, \mathrm{P}$ is the output price level of industry $i$ at time $t, r$ is the nominal bank lending rate at time $t$, and $\pi$ is the rate of inflation. As shown in figure 1, the ratio of average wage to rental price of capital rises for both registered manufacturing as a whole (All-w/r) and for labour-intensive manufacturing (LI-w/r). The ratio rises slowly until mid-1990 and then rises more rapidly after that with the ratio for labour-intensive industry increasing faster.

Figure 1. Ratio of wage to rental price of capital

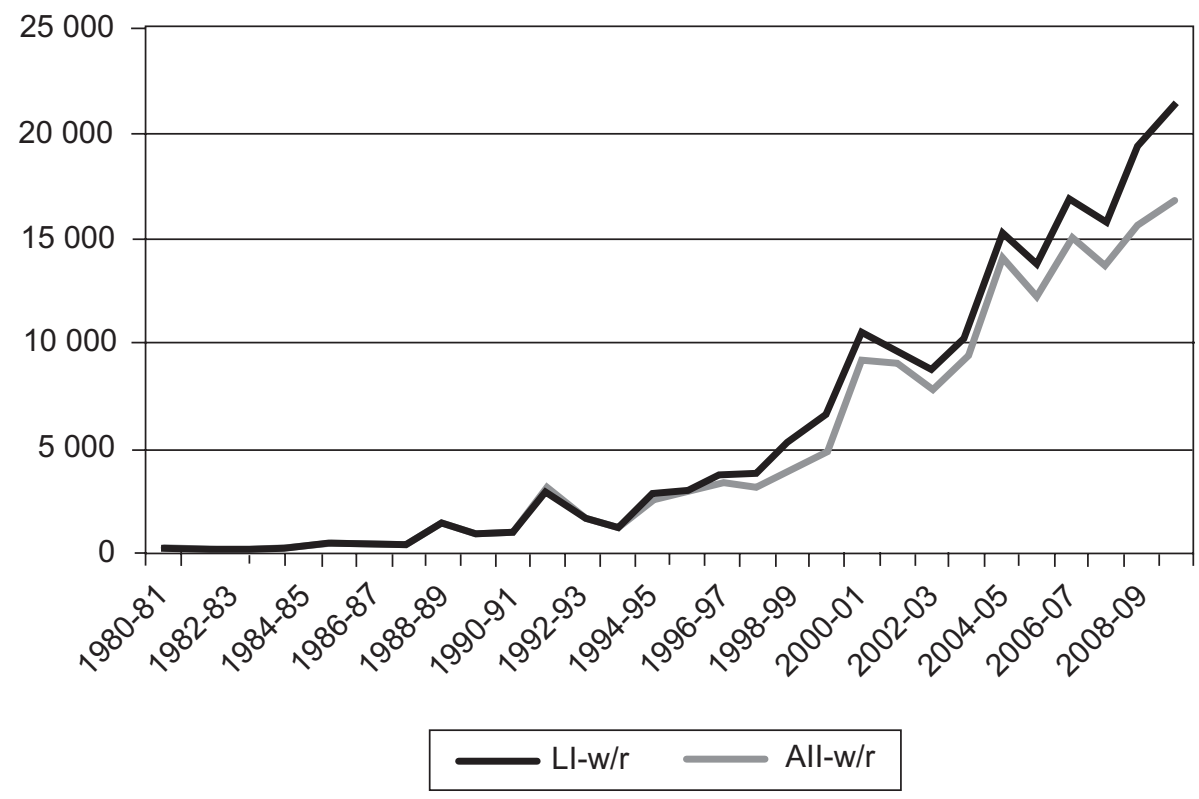

Source: Sen and Das (2014).

Notes: LI-w/r, wage to rental rate for labour-intensive industry; All-w/r, wage to rental rate for manufacturing as a whole. 
Now the interesting thing about these results concerns what it is driving the change in the ratio. It seems that real wages in manufacturing are rising while the rental price of capital is falling. Thus, the rise in the ratio is due to a rise in real wages and a fall in the rental price of capital. The latter began to decline in the early 1990s, while the former rose throughout the period (1980-2010) (Sen and Das, 2014). Figure 2 illustrates the rise in real wages.

\section{Figure 2. Real wage to rental rate for manufacturing as a whole}

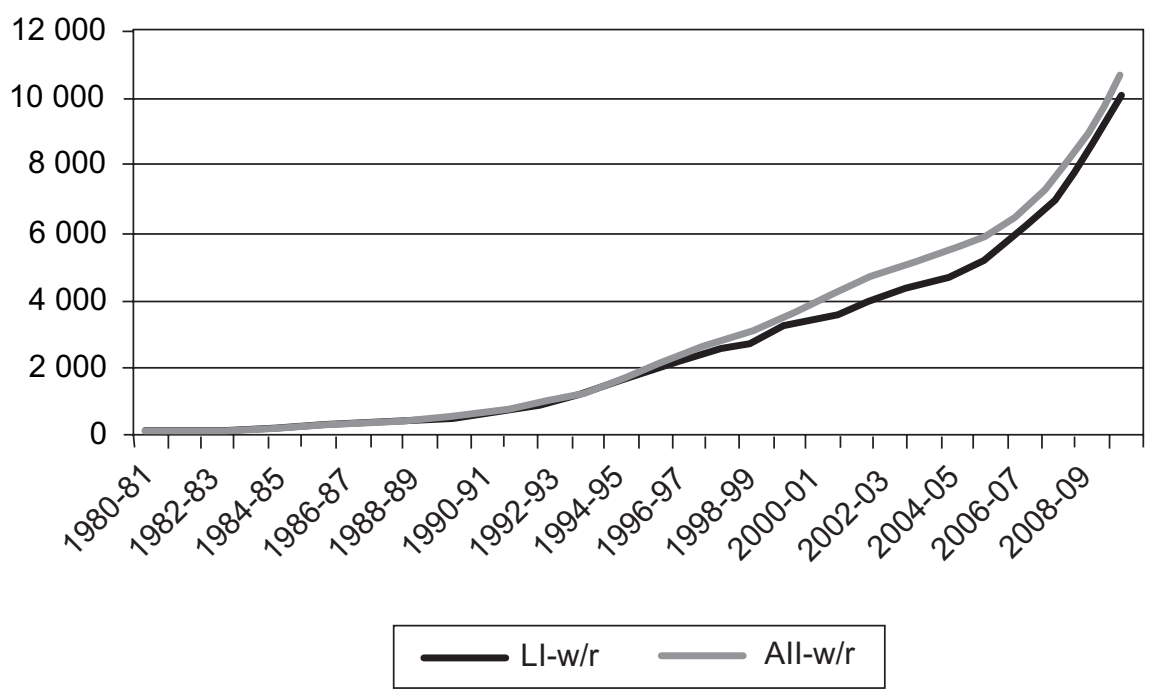

Source: Sen and Das (2014).

Notes: $\quad$ LI-w/r, wage to rental rate for labour-intensive industry; All-w/r, wage to rental rate for manufacturing as a whole.

Sen and Das (2014) attribute the fall in the rental price of capital to economic reforms undertaken in the early 1990s. The reforms led to a reduction in the nominal rate of protection for a variety of different types of capital goods. With declining protection, Indian firms could take advantage of the cheap capital goods available in international markets. This is related to arguments made earlier in this paper concerning factors that account for the lack of development of labour-intensive manufacturing. Specifically, technical innovation, which has enabled greater automation of even labour-intensive production processes, combined with a globalization process that has unbundled the manufacturing production process, has resulted in increased capital intensity and a dispersal of the supply chain in manufacturing. The analysis of Sen and Das (2014) supports this point of view. 
The focus of this paper is on the rise in the real wage rate in India. In the previous paragraph, the rising wage in manufacturing was discussed. However, it appears that real wages in agriculture, in particular farming, have also been increasing. In particular, from 1990-1991 to 2000-2001, the real wage rate rose at an annual rate of 3.7 per cent. From 2001 to 2002, the real wage rose at an annual rate of 2.1 per cent. However, from 2006 to 2007, the rate accelerated dramatically (Wiggins and Keats, 2014). In summary, the real wage rose in both the agriculture and manufacturing sectors. From this, the key question is what is driving this rise in real wages? One could speculate that the rise is the result of rapid economic growth that began with reforms undertaken in the 1980s and early 1990s. However, it has been pointed out earlier in the paper that the growth in the demand for labour has been very slow with the production process in manufacturing becoming increasingly capital intensive. Therefore, demand stemming from economic growth would seem to be an unlikely cause of a rise in real wages. It is argued here that at least part of the increase in real wages is the result of an increase in food prices.

In the previous section, it was shown theoretically that an increase in the price of food stimulates an expansion in food production, drawing labour from manufacturing by raising the real wage. Empirical evidence with respect to this issue in India is provided in the work of Jacoby (2013). Using wage data for India derived from the NSS Employment-Unemployment Survey for the period 2004-2009, he found that real wages for manual labour both within and outside agriculture rose with an increase in food producer prices. The wage increases were most rapid in the districts where prices increased the most.

There is evidence indicating that this relationship also holds in other places. Van Campenhout, Pauw and Minot (2013) have utilized data drawn from Uganda. They have found that in the short run a rise in food prices has a negative effect on household welfare. However, in the long run, the welfare levels of rural households rise sharply because of increased returns to household labour and farm land coupled with an increase in the prices of food commodities sold. Wiggins and Keats (2014) have found that this has been the case throughout much of Asia.

Farm prices, in particular the price of food, have increased over time in India. Table 4 presents data on the wholesale price index for all commodities (WPIAC), the wholesale price index for all agricultural items (WPIFA), and the consumer price index for industrial worker-food (CPIIWF). As indicated, not only did the last two indices (measuring agricultural and food price changes, respectively) increase over time, but they also rose more rapidly than the overall price index. 
Table 4. Price indices for India

\begin{tabular}{|c|c|c|c|}
\hline Year & WPIAC & WPIFA & CPIIWF \\
\hline 1982 & 100.00 & 100.00 & 100.00 \\
\hline 1983 & 104.90 & 111.00 & 102.30 \\
\hline 1984 & 112.80 & 127.00 & 117.60 \\
\hline 1985 & 120.10 & 132.00 & 122.00 \\
\hline 1986 & 125.40 & 134.00 & 128.00 \\
\hline 1987 & 132.70 & 148.00 & 141.00 \\
\hline 1988 & 143.50 & 161.00 & 152.00 \\
\hline 1989 & 154.20 & 177.00 & 169.00 \\
\hline 1990 & 165.70 & 179.00 & 177.00 \\
\hline 1991 & 182.70 & 201.00 & 199.00 \\
\hline 1992 & 207.80 & 241.00 & 230.00 \\
\hline 1993 & 228.70 & 271.00 & 254.00 \\
\hline 1994 & 247.80 & 284.00 & 272.00 \\
\hline 1995 & 276.64 & 320.92 & 304.00 \\
\hline 1996 & 298.87 & 346.48 & 337.00 \\
\hline 1997 & 313.69 & 389.08 & 369.00 \\
\hline 1998 & 326.04 & 400.44 & 388.20 \\
\hline 1999 & 345.80 & 451.56 & 445.00 \\
\hline 2000 & 358.15 & 471.44 & 446.00 \\
\hline 2001 & 382.85 & 485.64 & 453.00 \\
\hline 2002 & 397.67 & 499.84 & 466.00 \\
\hline 2003 & 410.02 & 508.36 & 477.00 \\
\hline 2004 & 432.25 & 516.88 & 495.00 \\
\hline 2005 & 461.89 & 528.24 & 506.00 \\
\hline 2006 & 479.44 & 554.40 & 527.00 \\
\hline 2007 & 511.71 & 612.48 & 575.00 \\
\hline 2008 & 535.76 & 654.72 & 620.63 \\
\hline 2009 & 580.86 & 712.80 & 698.21 \\
\hline 2010 & 599.30 & 818.40 & 803.17 \\
\hline 2011 & 659.23 & 950.40 & 885.32 \\
\hline 2012 & 719.16 & 1019.04 & 940.08 \\
\hline
\end{tabular}

Source: Adapted from Sasmal (2015). 
What was the cause of the rising relative price of food in India over the last several decades? From the 1980s onward, the rate of growth in GDP per capita has increased substantially. In addition, periods of negative annual growth have been relatively rare. Although Engel's law predicts that as the standard of living rises, households spend a smaller share of their budgets on food and food-related items, food remains a significant allocation in most family budgets in India. Thus, more rapid economic growth is likely to lead to rapid growth in the demand for food and related items. If domestic production fails to keep up and India represents a large country case, then indeed one would expect that food prices will be driven upward.

Sasmal (2015) utilizes time series data and the Granger causality analysis to determine whether growth in economic output per capita as measured by net national product per capita causes food prices increases. He utilizes data on the growth in the production of food grains, per capita net national product, expenditures by central and state governments, money supply, and changes in the exchange rate between the Indian rupee relative to the US dollar. The results of the analysis show that growth in net national product per capita significantly explains much of the food price inflation in India. The increase in real wages in both the agriculture and nonagriculture sectors stemming from rising food prices has played a role in making labour relatively more expansive than capital. This, in turn, has led to a reduction in the labour intensity of production processes, especially in manufacturing and particularly in labour-intensive manufacturing.

However, several other factors supporting the rising relative cost of food must be noted. Although expenditures on food have increased significantly as economic growth has occurred, the composition of those expenditures has begun to change. A greater share of expenditures is devoted to protein-rich foods and fruits and vegetables, while expenditures on food grains as a share of household budgets has begun to decline. Production of the former products has failed to keep pace with demand, which has increasingly made them the source of rising food prices (Bhattacharya, Rao and Gupta, 2014)

The problems involved with shifts in demand (sluggish supply response for, among others, fruits, vegetables and meat) are compounded by the minimum price support policies set by the government. These types of programmes are mainly aimed at food grains, such as rice, wheat, coarse cereals, and pulses. Table 5 shows the growth rate of minimum price supports compared to the growth of the wholesale price index for two different time periods. As indicated, minimum support prices began to rise at a very rapid rate during the period 2006-2012. This in itself tended to add to the rising food prices, in particular, those associated with rice, wheat, coarse cereals, and pulses. 


\section{Table 5. Growth of minimum support prices and wholesale prices}

\begin{tabular}{llcc}
\hline \multirow{2}{*}{ Commodity } & & \multicolumn{2}{c}{ Average annual growth rate (\%) } \\
\cline { 3 - 4 } & & 2001-2002 to 2006-2007 & 2007-2008 to 2012-2013 \\
\hline \multirow{2}{*}{ Rice } & MSP & 3.52 & 10.90 \\
\multirow{2}{*}{ Wheat } & WPI & 1.21 & 9.40 \\
& MSP & 2.46 & 9.69 \\
Coarse cereals & WPI & 3.55 & 6.66 \\
& MSP & 2.18 & 15.35 \\
Pulses & WPI & 5.49 & 11.22 \\
& MSP & 3.04 & 16.37 \\
& WPI & 6.68 & 8.49 \\
\hline
\end{tabular}

Source: Adapted from Bhattacharya, Rao and Gupta (2014).

Notes: $\quad$ MSP, minimum support price; WPI, wholesale price index.

An indirect effect of higher support prices has also occurred. Specifically, products subject to minimum price supports distort the allocation of resources among various food products. That is, the major food grains receive a support price whereas other agricultural products do not. This raises the relative price of the former relative to the latter and, consequently, causes resources to flow towards grain production and away from fruits and vegetables, among other products. Therefore, as income has grown in India, the demand for fruits, vegetables and meat has risen dramatically (relative to grains), while support price policies have allocated resources away from these high demand growth sectors. This has made inflation in food prices more intense.

In addition to the above, agricultural growth has lagged significantly behind the growth in the non-agricultural part of the economy. Between 2000-2001 and 2012-2013, non-agricultural GDP grew at an average annual rate of almost 8 per cent while agriculture grew at about 3 per cent, a considerable disparity. However, the growth of agriculture during this period was high in comparison to previous years. Even more important, the increase in yields has slowed dramatically. Data concerning these trends are presented in table 6.

As indicated in the table, rice and wheat production growth rates declined significantly, despite the application of minimum support prices, but rice yields grew only slightly and wheat yields declined. The production of fruit and vegetables was in accordance with the growth of demand, but yield growth of vegetables remained sluggish or actually fell. 


\section{Table 6. Annual growth of production and yields}

\begin{tabular}{lcccccc}
\hline \multirow{2}{*}{ Crop } & \multicolumn{2}{c}{ Production } & & \multicolumn{2}{c}{ Yields } \\
\cline { 2 - 3 } \cline { 5 - 6 } \cline { 5 - 6 } & 1990s & 2000s & & 1990s & 2000s \\
\hline Rice & 1.79 & 0.87 & & 1.40 & 1.50 \\
Wheat & 4.36 & 0.57 & & 2.90 & 1.10 \\
Pulses & -0.39 & 1.88 & & 1.80 & 1.20 \\
Fruits & 4.20 & 5.80 & & 0.70 & 0.70 \\
Vegetables & 4.20 & 5.40 & & 3.20 & 1.70 \\
\hline
\end{tabular}

Source: $\quad$ Adapted from Bhattacharya, Rao and Gupta (2014).

Thus, technical innovation has slowed dramatically in agriculture relative to the pace experienced during the "Green Revolution". Public expenditures in agriculture as a share of GDP remained stagnant in the 1990s and 2000s at about 2 to 3 per cent per year. Even more importantly, these public expenditures have been increasingly devoted to subsidies rather than the development of new technologies. By 2009-2010, nearly 80 per cent of public sector spending was in the form of subsidies. While power subsidies remained around 5 per cent of agricultural GDP from the mid-1990s to the late 2000s, fertilizer subsidies increased dramatically, jumping from about 1.7 per cent of agricultural GDP to about 8 per cent. The result is that technical innovation in agriculture has slowed considerably. Thus, the growth in demand for food items was met by sluggish growth in agricultural productivity. This, in turn, led to rapidly rising food prices with a corresponding effect on real wages in agriculture and non-agriculture sectors (Bhattacharya, Rao and Gupta, 2014).

Based on the above-mentioned analysis, it can be argued that real wages have been driven up as a result of a rise, over time, of food prices. However, there is another factor that has influenced real wages more directly, namely the Mahatma Gandhi National Rural Employment Guarantee Scheme (MGNREGS). The main objective of this programme was to enhance the economic stability of rural household income by providing at least 100 days of guaranteed employment to every household. This mainly involved unskilled manual labour. The programme was initially introduced in parts of India in 2006 and extended to all of the country by 2008 (Bhattacharya, Rao and Gupta, 2014).

This type of programme directly adds to upward pressure on the wage through an increase in the demand for labour. This, in turn, tends to boost the bargaining power of rural, unskilled workers, putting upward pressure on the real wage earned in agriculture, as well as on wages in manufacturing, especially those associated with 
labour-intensive manufacturing. These types of economic activities intensively require the use of lesser skilled labour, which is abundant in the countryside of India (Guha and Tripathi, 2014).

A number of papers have indeed found that this programme has exerted upward pressure on real wages. For example, Imbert and Papp (2012) used data from National Sample Survey Office (NSSO) to conclude that MGNREGS raised public works employment by 0.3 person day per month and casual wage income by 4.5 per cent. Berg and others (2012) used data from Agricultural Wages in India to find that MGNREGS increased agricultural wage rates by 5.3 per cent. As Gulati, Jain and Satiga (2013) noted, a 10 per cent increase in employment had pushed up agricultural wages by 0.3 per cent to 0.8 per cent. Thus, the empirical evidence indicates that the increased demand from this programme pushed up wages in rural areas in India.

It is not being argued in this paper that the employment guarantee scheme of India has reduced the welfare of unskilled workers in India. It seems that the opposite has occurred; their real earnings rose. The point being made here is that a side effect of this policy has been to make it more difficult for labour-intensive manufacturing to succeed. This would not have occurred if the productivity of agriculture had expanded in tandem with the employment guarantee. If this were to occur, labour costs associated with labour-intensive manufacturing would not need to increase and, consequently, the latter would not face increased difficulty in terms of being profitable. In addition, the increased income of unskilled workers would likely increase the demand for labour-intensive manufactured goods.

In this section, it has been argued that the process of structural change in India is much different from the process in many other countries or subregions, such as East Asia, China, and parts of South-East Asia. Typically, as economic growth occurs, the proportion of GDP and employment connected with agriculture declines (with the former generally falling more rapidly than the latter, at least initially). This is generally accompanied by rapid growth in labour-intensive manufacturing followed quickly by rapid growth in the modern service sector, with the share of these sectors in employment and GDP increasing. In India, labour-intensive manufacturing has not followed this pattern.

The simple reason offered for this phenomenon has been that the rise in the wage to capital rent ratio has resulted in labour becoming relatively more expensive relative to capital. This has occurred as a result of the decline in the rental rate of capital and a rise in the real wage rate of labour. This paper focuses on analysing the latter factor, the rise of real wages. Specifically, it was argued that rise in food prices driven by demand stemming from economic growth has resulted in rising real wages. 
The sluggishness in supply response to this growing demand is the critical factor. Supply side sluggishness is the result of slow rates of technical innovation in agriculture combined with the distortions created by the minimum support price policies adopted by the state. This has been exacerbated by an employment guarantee scheme. Again, to emphasize, the underlying problem is that the supply side of food production has not kept up with the growing demand.

In order to further test the ideas developed above, some additional empirical analysis was carried out. Lacking adequate data on wages for a long period, it was not possible to examine the impact of food prices on wages. However, adequate data are available for an examination of the relationship between food price increases and the share of manufacturing in GDP relative to the share of services in GDP. The equation that was estimated can be written as

$$
\text { MfgS/ServS }=\beta_{0}+\beta_{1}(\text { MfgS/ServS })_{\mathrm{t}-1}+\beta_{2} \text { CPIIWF }+\beta_{3} \text { GDPPGR }+\varepsilon
$$

where MfgS/ServS is the share of manufacturing in GDP divided by the share of services in GDP, (MfgS/ServS) $)_{-1}$ is the same variable lagged one time period, CPIIWF is the consumer price index for food for industrial workers, and GDPPGR is the growth rate of real per capita GDP. The data for GDP shares and growth of GDP per capita were taken from World Development Indicators. The data for CPIIWF come from the work of Sasmal (2015). The time period covered is from 1971 to 2012. It is expected that more rapid growth in real GDP per capita would be positively related to the ratio of the share of manufacturing in GDP to that of services, namely manufacturing would become more important (at least initially). The lagged value of the independent variable is included on the right hand side in order to reduce serial correlation. Finally, the argument made in this paper would imply that higher food prices would be associated with a reduction in the share of manufacturing relative to services in GDP.

The results of the estimation are presented in table 7. As indicated, the sign on GDPPGR is positive, but it is not statistically significant. The sign on CPIIWF is negative and statistically significant, as hypothesized. Thus, rising food prices are associated with a decline in the importance of manufacturing relative to services. 
Table 7. Estimation results: manufacturing as a share of GDP relative to services as a share of GDP as the dependent variable

\begin{tabular}{lc}
\hline \multicolumn{1}{c}{ Variable } & Coefficient \\
\hline (MfgS/ServS $)_{\mathrm{t}-1}$ & $0.6662^{\star \star *}$ \\
& $(0.113)$ \\
CPIIWF & $-0.00008^{\star \star *}$ \\
& $(0.00003)$ \\
GDPPGR & 0.02697 \\
& $(0.07877)$ \\
Constant & $0.1333^{\star \star}$ \\
& $(0.04528)$ \\
Observations & 40 \\
\hline Notes: $\quad$ Standard error for each coefficient value is given in parentheses. \\
$\quad$ ** Signifies significance at the $5 \%$ level, and ${ }^{* \star *}$ signifies significance \\
$\quad$ at the $1 \%$ level.
\end{tabular}

\section{SUMMARY AND CONCLUSION}

Structural change in India and the particular path it has taken has been the focus of this paper. Theoretical models, including a food production sector, manufacturing and services (both modern and traditional) were constructed. The implication of those models was that a rise in food prices will, among other things, cause resources to flow out of manufacturing. In particular, wages would rise in agriculture, drawing labour out of manufacturing and into food-producing agriculture. However, the increased wage rate is likely to lead to increased mechanization of agriculture in the long run, implying that the growth in employment opportunities in this sector may slow. Thus, labour-intensive informal service activities in rural areas are likely to grow. This occurs even in an open economy context in which the large country case is assumed. A second model incorporating modern services as the export sector (human capital intensive) has a similar implication. Expansion in this sector (growth in income) would lead to an increase in expenditures on manufacturing and food. The manufactured goods would be increasingly imported as the real wage in agriculture is driven up and labour flows into food production and rural-based informal service production and away from manufacturing. The overall conclusion is that as long as food productivity remains sluggish, economic growth would increase the relative cost of labour and labour-intensive manufacturing would be less and less likely to be competitive. Thus, growth would not generate rapid expansion in employment. 
The experience of India was utilized to illustrate the process outlined in the theory. Evidence was presented to show that labour had become relatively more expensive, reducing labour-intensive manufacturing. The rise in the relative price of labour was shown to be partly the result of rising food prices stemming from rapid growth in demand (stimulated by overall growth) compared to sluggish growth in agricultural productivity. These trends were exacerbated by the minimum price support policy and the employment guarantee programme. The latter may have enhanced the welfare of unskilled rural labour, but the unexpected consequence was rising food prices and rural labour becoming more expensive. These effects would have been mitigated by rapid growth in agricultural productivity.

Before closing, it should be pointed out that the ability of increased agricultural productivity, especially in food, to enhance the development of manufacturing through relatively cheap food may be limited by the existing structure of the economy. Countries that have already developed substantial modern service sectors, such as India, and have bypassed labour-intensive manufacturing may find it difficult to shift to an alternative path. Broad-based development may, as a result, involve creating a high wage, highly productive agricultural sector with a rural-based highly productive service sector. Agriculture would continue to employ a high share of the population for some time with income per person in that sector approaching the rate earned in urban areas. This kind of development path is being examined in some of the most recent research (Dorin, Hourcade and Benoit-Cattin, 2013). 


\section{REFERENCE}

Amirapu, Amrit, and Arvind Subramanian (2015). Manufacturing or services? An Indian illustration of a development dilemma. Working Paper, No. 409. Washington, D.C.: Center for Global Development.

Baldwin, Richard (2011). Trade and industrialisation after globalisation's $2^{\text {nd }}$ unbundling: how building and joining a supply chain are different and why it matters. Working Paper, No. 17716. Cambridge, MA: National Bureau of Economic Research.

Berg, Erlend, and others (2012). Can rural public works affect agricultural wages? Evidence from India. Working Paper Series, WPS/2012-05. Oxford, U.K.: Centre for the Study of African Economies, Oxford University.

Bhattacharya Rudrani, Narhari Rao, and Abhijit Sen Gupta (2014). Understanding food inflation in India. South Asia Working Paper Series, No. 26. Manila: Asian Development Bank.

Binswanger-Mkhize, Hans Peter, and Alwin D'Sousa (2011). Structural transformation of the Indian economy and its agriculture. In Productivity Growth in Agriculture: An International Perspective, K.O. Fuglie, S.L. Wang and V. Eldin Ball, eds. Oxfordshire, U.K.: CAB International.

Dorin, Bruno, Jean-Charles Hourcade, and Michel Benoit-Cattin (2013). A world without farmers? The Lewis path revisited. Working Paper, No. 24-2013. Nogent-sur-Marne, France: Centre International de Recherches sur l'Environnement et le Developpement.

Felipe, Jesus, Aashish Mehta, and Changyong Rhee (2014). Manufacturing matters...but it's the jobs that count. Economics Working Paper Series, No. 420. Manila: Asian Development Bank.

Gollin, Douglas, Remi Jedwab, and Dietrich Vollrath (2013). Urbanization with and without industrialization. Journal of Economic Growth, vol. 21, No. 21, pp. 35-70.

Gollin, Douglas, Stephen L. Parentz, and Richard. Rogerson (2007). The food problem and the evolution of international income levels. Journal of Monetary Economics, vol. 54, Issue 4, pp. $1230-1255$.

Guha, Atulan, and Ashutosk K.R. Tripathi (2014). Link between food price inflation and rural wage dynamic. Economic and Political Weekly, vol. 49, No. 26 and 27, pp. 66-72.

Gulati, Ashok, Surbhi Jain, and Nidhi Satiga (2013). Rising farm wages in India: the 'pull' and 'push' factors. Discussion Paper, No. 5. New Delhi: Commission for Agricultural Costs and Prices.

Imbert, Clément, and John Papp (2012). Equilibrium distributional impacts of government employment programs: evidence from India's employment guarantee. Paris School of Economic Working Paper, No. 2012-2014. Paris: Centre National de la Recherche Scientifique.

Jacoby, Hanan (2013). Food prices, wages, and welfare in rural India. Policy Research Working Paper, No. 6412. Washington, D.C.: World Bank.

Kochhar, Kalpana, and others (2006). India's pattern of development: what happened, what follows? Journal of Monetary Economics, vol. 53, No. 5, pp. 981-1019.

Lewis, W. Arthur (1954). Economic development with unlimited supplies of labour. The Manchester School, vol. 22, No. 2, pp. 139-191.

Reddy, Amarender (2015). Growth, structural change, wage rates in rural India. Economic and Political Weekly, vol. 1, No. 2, pp. 56-65 (January), pp. 56-65. 
Ricardo, David (1965). On the Principles of Political Economy and Taxation. London: Everyman's Library.

Rodrik, Dani (2013). Unconditional convergence in manufacturing. Quarterly Journal of Economics, vol. 128 , No. 1 , pp. $165-204$.

(2014). Has sustained growth decoupled from industrialization? Presentation presented at the Frontier Issues in Economic Growth: A Symposium from the Growth Dialogue. George Washington University, Washington, D.C., 10 February. Available from https:// dinmerican.wordpress.com/2014/04/09/dani-rodrik-has-sustained-growth-decoupledfrom-industrialization/.

Sasmal, Joydeb (2015). Food price inflation in India: the growing economy with sluggish agriculture. Journal of Economics, Finance and Administrative Science, vol. 20, No. 38, pp. 30-40.

Sen, Kunal, and Deb Kusum Das (2014). Where have all the workers gone? The puzzle of declining labor intensity in organized Indian manufacturing. Development Economics and Public Policy Working Paper Series, No. 35/2014. Manchester: University of Manchester, Institute for Development Policy and Management.

Van Campenhout, Bjorn, Karl Pauw, and Nicholas Minot (2013). The impact of food price shocks in Uganda: first order versus long-run effects. Discussion Paper, 01284. Washington, D.C.: International Food Policy Research Institute.

Wiggins, Steve, and Sharada Keats (2014). Rural Wages in Asia. London: Overseas Development Institute. 